\title{
Fully bioresorption of an Absorb bioresorbable vascular scaffold after scaffold restenosis
}

\author{
Luis R. Goncalves-Ramírez ${ }^{1}$, Hipólito Gutiérrez ${ }^{1,2}$, Paol Rojas ${ }^{1}$, \\ Carlos Cortés ${ }^{1}$, Ana Serrador ${ }^{1,2}$, Benigno Ramos ${ }^{1}$, Jairo Toro ${ }^{1}$, \\ Ignacio J. Amat-Santos ${ }^{1,2}$, José A. San Román ${ }^{1,2}$ \\ ${ }^{1}$ CIBERCV, Hospital Clínico Universitario, Valladolid, Spain \\ ${ }^{2}$ Institute of Heart Sciences, Hospital Clínico Universitario, Valladolid, Spain
}

A 72-year-old man with hypertension, dyslipidemia, diabetes mellitus and atrial fibrillation underwent coronary angiography due to unstable angina in 2012. A two-vessel disease was found and percutaneous coronary revascularization was performed. Mid left anterior descending (LAD) and distal right coronary artery (RCA) were treated with $3 \times 28 \mathrm{~mm}$ and $2.5 \times 18 \mathrm{~mm}$ bioresorbable vascular scaffolds, respectively (Absorb BVS, Abbott Vascular, Santa Clara, CA, USA). Although this was probably not the best case for bioresorbable scaffold implantation, Absorbs BVS were used due to the apparent technical simplicity of these two lesions and the hypothetical benefit of bioresorbable technology in case of future anastomosis of bypass grafts. Pre-dilatation and high pressure post-dilatation were performed with non-compliant balloons in both cases. The final result was evaluated with optical coherence tomography (OCT), which showed a short segment of mild underexpansion in RCA (minimal scaffold area after post dilation $4.01 \mathrm{~mm}^{2}$ ) and an optimal result in LAD (Fig. 1, Panels A-1.1, A-1.2, A-1.3). The patient was discharged 4 days later on dual antiplatelet therapy, beta-blockers, angiotensin-converting enzyme inhibitors and statins.

Six months later, the patient was readmitted due to a new episode of unstable angina. A new coronary catheterization showed a restenosis of the distal RCA scaffold, without restenosis of LAD BVS or any other coronary lesion. BVS restenosis was pre-dilated with an AngioSculpt balloon (AngioScore, CA, USA); then, a $2.5 \times 28 \mathrm{~mm}$ everolimus- eluting stent (Xience, Abbott Laboratories, Abbott Park, IL, USA) was implanted. An OCT analysis was performed before and after drug-eluting stent (DES) implantation and showed that restenosis was located at the zone of the initial under-expansion (Fig. 1, Panels A-2.1, A-2.2, A-2.3).

The patient underwent left atrial appendage closure and pacemaker implantation in 2014. In 2017, he was again readmitted to hospital complaining of dyspnea and atypical chest pain. Due to his past medical history, he underwent a new coronary catheterization in order to discard a new restenosis or coronary lesion. There was no evidence of new lesions or restenosis after coronary angiography, so a new OCT analysis was performed over the scaffolded segments of RCA and LAD.

Bioresorbable vascular scaffold were completely reabsorbed in both LAD and RCA with adequate development of a new neointimal layer. A signal-rich layer development was observed in LAD, which corresponds to neointima and underlaying tissue in OCT image (Fig. 1, Panels B-3.1, $\mathrm{B}-3.2, \mathrm{~B}-3.3)$. On the other hand, this pattern was not seen in RCA because of the previously implanted DES. In this case, and thanks to BVS bioresorption, RCA looked like a common stented artery evaluated by OCT after metallic stent endothelization (Fig. 1, Panels A-3.1, A-3.2, A-3.3).

Absorb BVS was one of the first bioresorbable scaffolds to be developed and it was ready for use in most European countries in 2012 [1]. The first studies showed good long-term outcomes with this device $[2,3]$, but safety has been questioned re-

Address for correspondence: Luis Renier Goncalves-Ramírez, MD, Instituto de Ciencias del Corazón (ICICOR), Hospital Clínico Universitario de Valladolid, Ramón y Cajal 3. 47005. Valladolid, Spain, tel: +34 9834200 26, fax: +34 9832553 05, e-mail: luisrenier@hotmail.com 


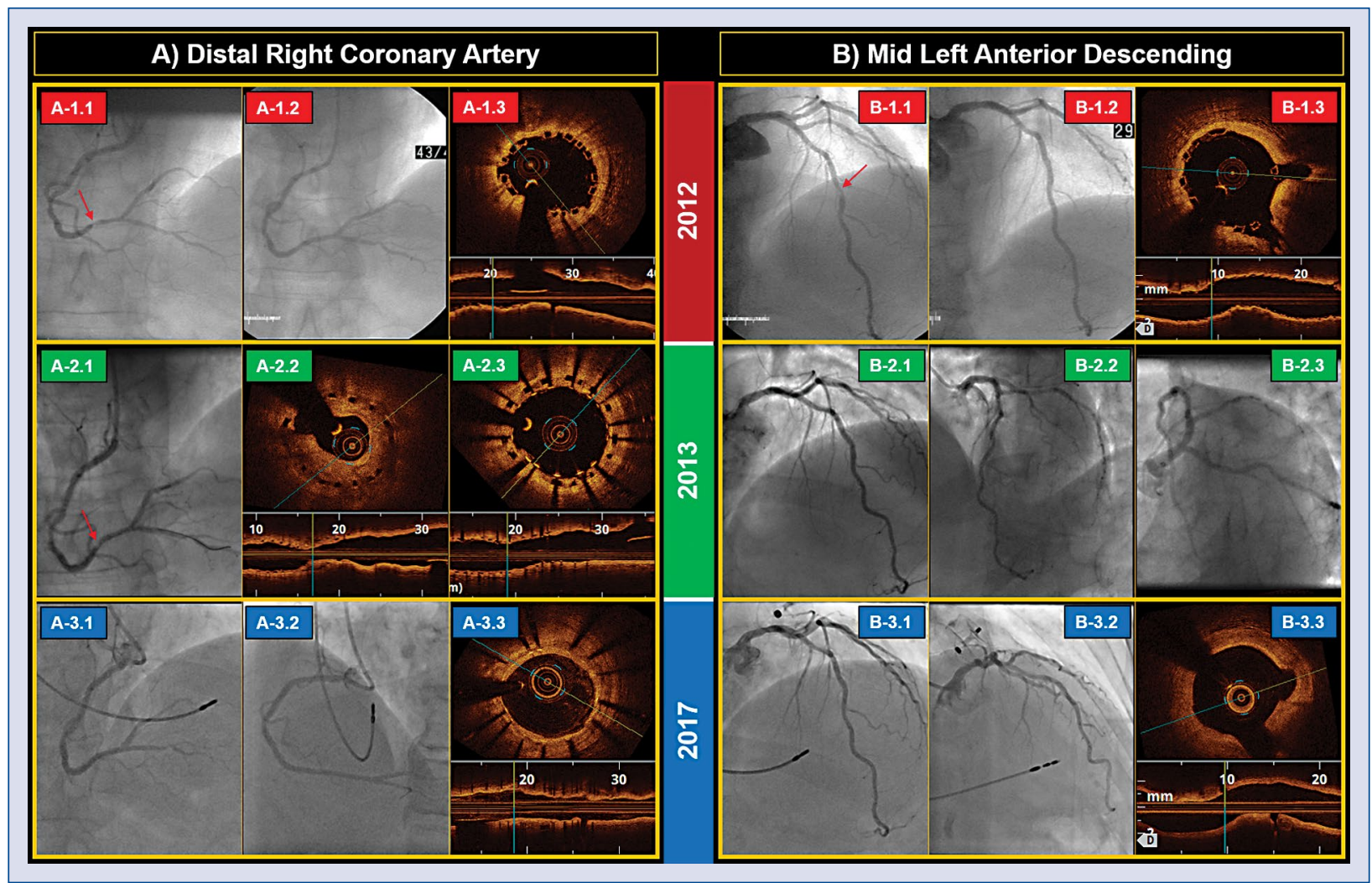

Figure 1. Coronary angiography and optical coherence tomography (OCT) findings after scaffold implantation. A. Right coronary artery (RCA): A-1.1. A severe lesion of distal RCA (red arrow); A-1.2. Result after scaffold implantation; A-1.3. Under-expanded Absorb by OCT. A-2.1. A severe in-bioresorbable scaffold implantation (BVS) restenosis in distal RCA (red arrow); A-2.2, A-2.3. OCT findings before and after restenosis treatment with drug-eluting stent implantation. A-3.1, A-3.2, A-3.3. Angiography and OCT findings at 5-year follow-up. B. Left anterior descending (LAD): B-1.1. Severe lesion of mid LAD (red arrow); B-1.2. Result after scaffold implantation; B-1.3. Normal position of scaffold by OCT. B-2.1, B-2.2, B-2.3. Normal coronary angiography without BVS restenosis in 2013. B-3.1, B-3.2, B-3.3. Angiography and OCT findings at 5-year follow-up.

cently. In this regard, differing long-term follow-up trials suggest that BVS is associated with a higher incidence of thrombosis and myocardial infarction [4-6]. However, these adverse results may be related to an improper implantation technique and some technical aspects of the scaffold itself such as large profile, thick stent strut, scaffold deformation during the resorption period, and other issues [7]. In this context, intensive research is ongoing worldwide to clarify the importance of implantation technique for long-term results of this scaffold in the real world [8]. Nonetheless, there is not enough information about BVS bioresorption apart from ABSORB studies. BVS bioresorption has only been demonstrated in vivo by OCT after long-term follow-up in cohort A and B of the ABSORB stud- ies $[9,10]$. In this case, OCT findings after 5-year follow-up of actual patients previously treated with Absorb BVS and complicated with early scaffold restenosis, only one of them showed full reabsorption of both BVS.

In summary, fully bioresorption of Absorb BVS was found at 5-year follow-up in both scaffolded arteries, regardless of in-BVS restenosis. After scaffold resorption, an adequate healing process with signal-rich development was observed in LAD, while this pattern was less evident in RCA because of the previously implanted DES. In this context, DES implantation is a good therapeutic option for BVS restenosis.

Conflict of interest: None declared 


\section{References}

1. Byrne RA, Stefanini GG, Capodanno D, et al. Report of an ESC-EAPCI Task Force on the evaluation and use of bioresorbable scaffolds for percutaneous coronary intervention: executive summary. EuroIntervention. 2018; 13(13): 1574-1586, doi: 10.4244/ /EIJ20170912-01, indexed in Pubmed: 28948934.

2. Onuma Y, Dudek D, Thuesen L, et al. Five-year clinical and functional multislice computed tomography angiographic results after coronary implantation of the fully resorbable polymeric everolimus-eluting scaffold in patients with de novo coronary artery disease: the ABSORB cohort A trial. JACC Cardiovasc Interv. 2013; 6(10): 999-1009, doi: 10.1016/j.jcin.2013.05.017, indexed in Pubmed: 24156961.

3. Serruys PW, Ormiston JA, Onuma Y, et al. A bioabsorbable everolimus-eluting coronary stent system (ABSORB): 2-year outcomes and results from multiple imaging methods. Lancet. 2009; 373(9667): 897-910, doi: 10.1016/S0140-6736(09)60325-1, indexed in Pubmed: 19286089.

4. Brugaletta S, Gori T, Low AF, et al. Absorb bioresorbable vascular scaffold versus everolimus-eluting metallic stent in ST-segment elevation myocardial infarction: 1-year results of a propensity score matching comparison: the BVS-EXAMINATION Study (bioresorbable vascular scaffold-a clinical evaluation of everolimus eluting coronary stents in the treatment of patients with ST-segment elevation myocardial infarction). JACC Cardiovasc Interv. 2015; 8(1 Pt B): 189-197, doi: 10.1016/j.jcin.2014.10.005, indexed in Pubmed: 25616924.

5. Serruys PW, Chevalier B, Dudek D, et al. A bioresorbable everolimus-eluting scaffold versus a metallic everolimus-eluting stent for ischaemic heart disease caused by de-novo native coronary artery lesions (ABSORB II): an interim 1-year analysis of clinical and procedural secondary outcomes from a randomised controlled trial. Lancet. 2015; 385(9962): 43-54, doi: 10.1016/S01406736(14)61455-0, indexed in Pubmed: 25230593.

6. Wykrzykowska J, Kraak R, Hofma S, et al. Bioresorbable Scaffolds versus Metallic Stents in Routine PCI. N Engl J Med. 2017; 376(24): 2319-2328, doi: 10.1056/nejmoa1614954.

7. Stone GW, Gao R, Kimura T, et al. 1-year outcomes with the Absorb bioresorbable scaffold in patients with coronary artery disease: a patient-level, pooled meta-analysis. Lancet. 2016; 387(10025): 1277-1289, doi: 10.1016/S0140-6736(15)01039-9, indexed in Pubmed: 26825231.

8. Gutiérrez-Chico JL, Cortés C, Schincariol M, et al. Implantation of bioresorbable scaffolds under guidance of optical coherence tomography: feasibility and pilot clinical results of a systematic protocol. Cardiol J. 2018; 25(4): 443-458, doi: 10.5603/ /CJ.a2018.0055, indexed in Pubmed: 29774520.

9. Karanasos A, Simsek C, Gnanadesigan M, et al. OCT assessment of the long-term vascular healing response 5 years after everolimus-eluting bioresorbable vascular scaffold. J Am Coll Cardiol. 2014; 64(22): 2343-2356, doi: 10.1016/j.jacc.2014.09.029, indexed in Pubmed: 25465421.

10. Suwannasom P, Sotomi Y, Asano T, et al. Change in lumen eccentricity and asymmetry after treatment with Absorb bioresorbable vascular scaffolds in the ABSORB cohort B trial: a five-year serial optical coherence tomography imaging study. EuroIntervention. 2017; 12(18): e2244-e2252, doi: 10.4244/EIJ-D-16-00740, indexed in Pubmed: 27993756. 